\title{
Hydrogen: From a Biologically Inert Gas to a Unique Antioxidant
}

\author{
Shulin Liu, Xuejun Sun and Hengyi Tao \\ Second Military Medical University,
}

China

\section{Introduction}

Hydrogen gas $\left(\mathrm{H}_{2}\right)$, a colorless, tasteless, odorless, non-irritating and highly flammable diatomic gas, has been used in medical applications to prevent decomposition sickness in deep divers. For a long time, $\mathrm{H}_{2}$ was thought to be a "biologically inert gas" which could not react with biomolecules under normal pressure. In 2007, Ohsawa et al. first reported that inhalation of $\mathrm{H}_{2}$ markedly suppressed brain injury induced by ischemia-reperfusion, which made the antioxidant properties of $\mathrm{H}_{2}$ drew wide attention (Ohsawa et al., 2007). Soon afterwards $\mathrm{H}_{2}$ was found to be effective for many other diseases, including hepatic and cardiac hypoxia-ischemia injury, inflammation injury caused by small intestine transplantation, neonatal hypoxia-ischemia injury, and lung allograft, (Fukuda et al., 2007; Buchholz et al., 2008; Cai et al., 2008; Hayashida et al., 2008; Kawamura et al., 2011;). Besides, other ways to administrate $\mathrm{H}_{2}$, such as drinking $\mathrm{H}_{2}$-saturated water, intraperitoneal and intravenous injection of $\mathrm{H}_{2}$-saturated saline (first developed by our group), have also been proved to be effective to many disorders related with oxidative stress, such as cerebral hypoxia-ischemia injury, human type II diabetes, nephrotoxicity induced by cisplatin, Parkinson's disease and atherosclerosis in apolipoprotein (Cai et al., 2009; Chen et al., 2009; Mao et al., 2009; Sun et al., 2009; Zheng et al., 2009; Oharazawa et al., 2010). Up to now, $\mathrm{H}_{2}$ has been proved to be effective to various disease models. Considering the unique antioxidant properties of $\mathrm{H}_{2}$, we believe it is important to review the medical researches of this novel antioxidant in this chapter. The aim of this chapter is to summarize research findings and mechanisms concerning the therapeutic potential of $\mathrm{H}_{2}$.

\section{Physical, chemical and biological characteristics of $\mathbf{H}_{2}$}

The most lightweight gas diatomic hydrogen, the first element in the periodic table and constitutes at least $90 \%$ of the observable universe, is rare on earth. In 1671, Robert Boyle firstly produced hydrogen when he dissolved iron in diluted hydrochloric acid. However, it was not actually discovered as a distinct gas until 1766 when Henry Cavendish originally segregated and called it "inflammable air". A few years later, Lavoisier, the father of modern chemistry, gave it a name "hydrogen". Hydrogen is a colorless, odorless, nonmetallic, tasteless and highly combustible diatomic gas with the molecular formula $\mathrm{H}_{2}$ (Huang et al., 2010). Hydrogen gas directly and violently reacts with oxidizing elements such as chlorine and fluorine and is highly flammable, a property evident in the 1937 
Hindenburg zeppelin fire and its use as propellant fuel for the space shuttle. However, safe hydrogen concentrations in air and in pure oxygen gas are $4.6 \%$ and $4.1 \%$ by volume, respectively (Huang et al., 2010). On the other hand, $\mathrm{H}_{2}$ is rather less active and behaves as an inert gas in the absence of catalysts or at body temperature (Ohta, 2011). As hydrogen is a highly potent energy source, the industrial use of hydrogen is expanding, such as the use of hydrogen fuel cells for zero-emission vehicles (Nakao et al., 2009). $\mathrm{H}_{2}$ can be dissolved in water to $0.8 \mathrm{mM}$ under atmospheric pressure, and aluminum containers are able to retain hydrogen gas for a long time (Ohta, 2011). Hydrogen gas is highly diffusible and reacts with hydroxyl radical to produce water.

\section{The history of medical researches and application of $\mathrm{H}_{2}$}

For a long time, it has been believed that hydrogen did not react with biomoleculars. Hydrogen gas is routinely administered to divers as hydreliox, which contains $49 \%$ hydrogen (Abraini, 2011), to prevent decompression sickness. In 1975 and 2001, Dole and Gharib respectively reported that hydrogen under a high pressure might be a therapeutic gas for cancer and parasite-induced liver inflammation by eliminating toxic ROS (Dole et al., 1975; Gharib et al., 2001). In 2007, Ohsawa set out to see if hydrogen gas could be used as a therapeutic mitochondrial antioxidant to neutralize oxidative stress after ischemia reperfusion injury (Ohsawa et al., 2007). In these studies, Ohsawa found that hydrogen could increase cell survival significantly and hydrogen gas could reach sub-cellular compartments such as the nucleus and mitochondria. This is particularly important as mitochondria is the primary site of generation of reactive oxygen species after reperfusion and is notoriously difficult to target. To test the efficacy of hydrogen gas therapy during oxidative stress, Ohsawa et al. used a rat model of stroke, with middle cerebral artery ligation and reperfusion. Inhalation of hydrogen gas limited the stroke volume if given before the reperfusion phase of injury. Hydrogen gas treatment also reduced brain tissue lipid peroxidation and DNA oxidation, findings that were also noted in cultured cells challenged with reactive oxygen species. The decrease in reperfusion damage improved long term neurological function, such as thermoregulation and weight maintenance, at one week, implying that hydrogen gas can protect cells in vivo. Soon after that, the medical value of hydrogen rapidly drew wide attention in the world. $\mathrm{H}_{2}$ was found to produce some positive therapeutic outcomes in other diseases of various systems, such as central nervous system, cardiovascular system, lung, renal system, liver, pancreas, and auditory system (Huang et al., 2010), as shown in Fig. 1.

\section{Potential mechanisms of $\mathrm{H}_{2}$ as an antioxidant based on informed researches}

To explore the mechanism of the protective effect of hydrogen, Ohsawa and his coworkers treated PC12 cells with antimycin A (a mitochondrial respiratory complex III inhibitor) to produce hydroxyl radicals $(\bullet \mathrm{OH})$ by the Fenton reaction (Ohsawa et al., 2007). In the presence of $\mathrm{H}_{2}$ in the medium, the intracellular levels of $\bullet \mathrm{OH}$ and ONOO- were significantly reduced. Biochemical experiments using fluorescent probes and electron paramagnetic resonance spectroscopy spin traps indicated that hydrogen gas might selectively scavenge the hydroxyl radical. The authors propose this as a unique cyto-protective pathway that 


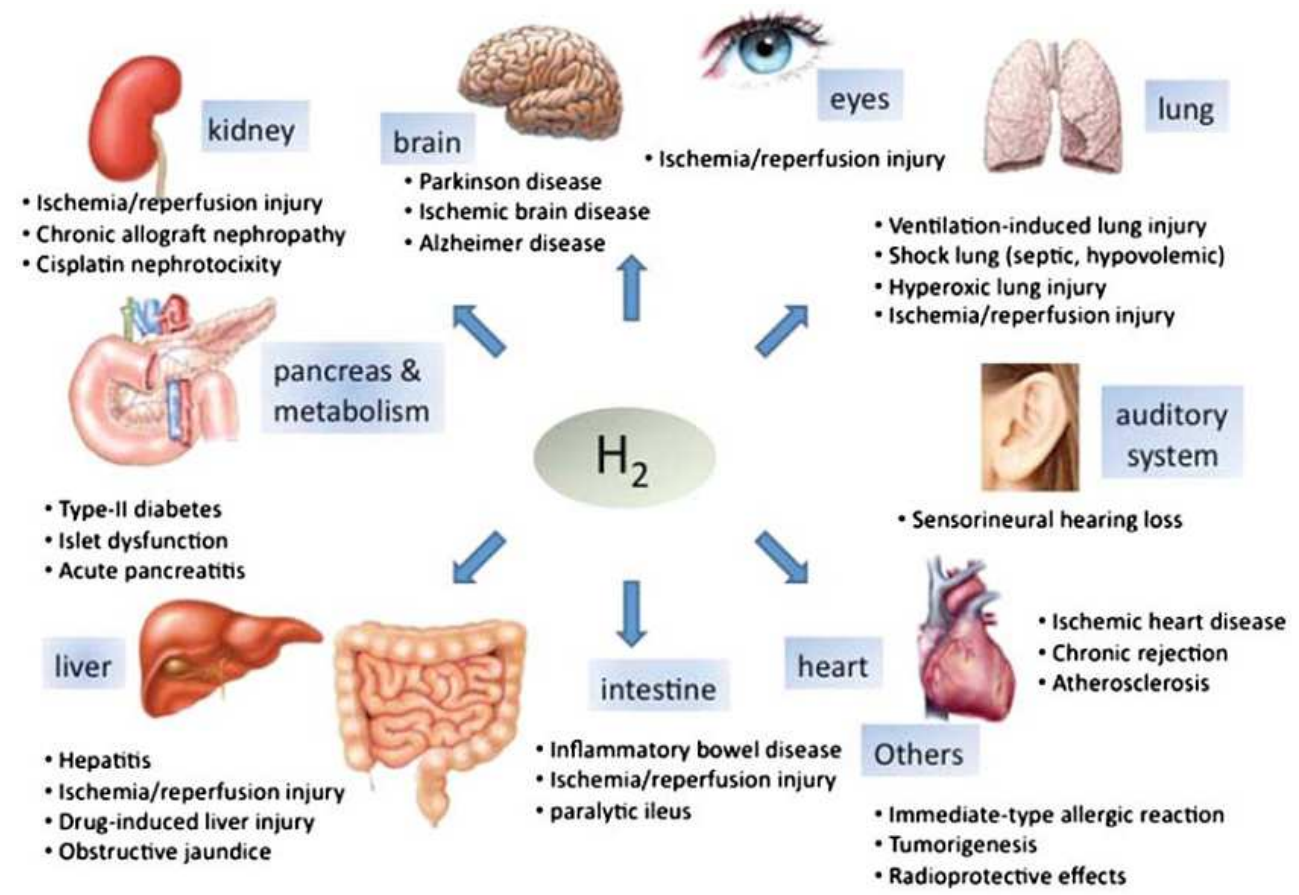

Fig. 1. Therapeutic opportunities of $\mathrm{H}_{2}$ in a variety of disease models (Huang et al., 2010).

specifically quenches the $\bullet \mathrm{OH}$ and $\mathrm{ONOO}^{-}$while preserving other reactive oxygen and nitrogen species important in signaling. Many antioxidants or enzymes that scavenge reactive oxygen species limit cyto-toxicity after ischemia and reperfusion. In the presence of catalytically active metals, however, detoxification of superoxide to hydrogen peroxide by superoxide dismutase generates the more potent hydroxyl radical. $\bullet \mathrm{OH}$ and $\mathrm{ONOO}-$ react indiscriminately with and damage molecular targets such as nucleic acids, lipids and proteins. Based on these evidence, Ohsawa et al. drew the conclusion that hydrogen gas protected cells from oxidative damage through selective scavenging of $\bullet \mathrm{OH}$ and $\mathrm{ONOO}-$, as shown in Fig. 2.

However, accumulating evidence suggest that hydrogen may be not a simple ROS scavenger. There were reports that treatment with $\mathrm{H}_{2}$ was unable to scavenge $\bullet \mathrm{OH}$ (Atsushi et al., 2010). As suggested by Wood and Gladwin (2007), the concentrations of hydrogen may be insufficient to protect the numerous cellular targets of $\bullet \mathrm{OH}$. In addition, $\mathrm{H}_{2}$ has been demonstrated to be effective for many diseases, but $\bullet \mathrm{OH}$ and other ROS are not the only cause of injury for all these diseases. This indicates that $\bullet \mathrm{OH}$ scavenging may not be the only underlying mechanism for the protective effects of $\mathrm{H}_{2}$ for those diseases where oxidative stress plays a less important role in the pathogenesis. A number of more recent investigations have reported that $\mathrm{H}_{2}$ might influence signal transduction (Itoh et al., 2009; Wang et al., 2011), suggesting that hydrogen may act as a novel signaling molecule rather than a ROS scavenger. Itoh and his associates found that $\mathrm{H}_{2}$ could modulate the immediatetype allergic reaction, which is not causally associated with oxidative stress (Itoh et al., 2009). In another study, $\mathrm{H}_{2}$ was found to inhibit lipopolysaccharide/interferon $\gamma$-induced 


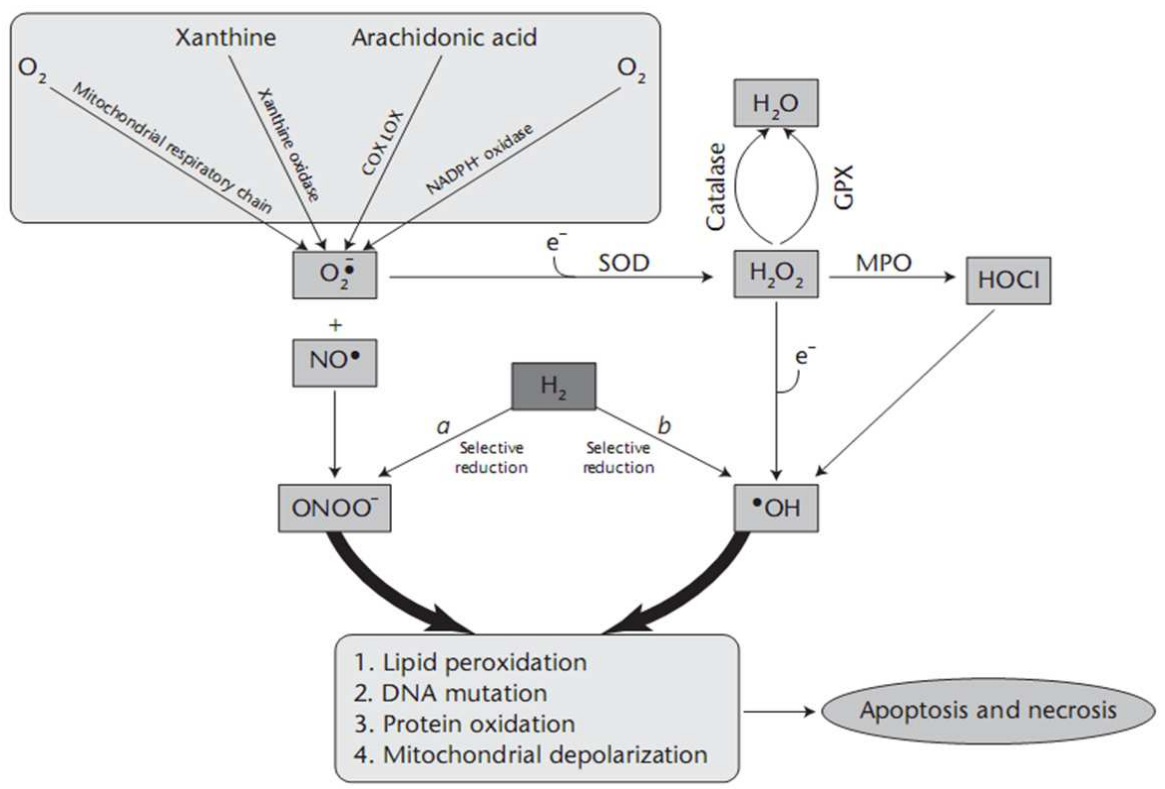

Fig. 2. The reactive oxygen species (ROS) production pathway and the selective reduction of - $\mathrm{OH}$ and $\mathrm{ONOO}-$ by $\mathrm{H}_{2}$ (Hong et al., 2010).

nitric oxide production through modulation of signal transduction in macrophages (Itoh et al., 2011). All these evidences imply that the effect of hydrogen may reside not in its radicalscavenging activity but in its ability to modulate a specific signaling pathway. Additionally, there is evidence of endogenous hydrogen in human and animals from anaerobic metabolism of bacteria in the large intestine (Sobko et al., 2005). In the normal terminal breath, levels of $\mathrm{H}_{2}$ are in the range 5-10 ppm (Maffel et al., 1977) ; in the liver, it reaches 42 $\mu \mathrm{M}$, while in the large intestine and spleen, it is even higher (Olson \& Maier, 2002) . The existence of endogenous hydrogen also suggests that hydrogen may be capable of exerting biological effects in physiological and pathological conditions in a manner similar to NO, $\mathrm{CO}$ and $\mathrm{H}_{2} \mathrm{~S}$. However, much additional research is required prior to verification, such as characterizing the molecular mechanism of hydrogen's effects.

\section{Methods for $\mathrm{H}_{2}$ administration}

\subsection{Inhalation}

For a long time, hydrogen inhalation has been applied in deep diving to prevent decompression sickness and nitrogen narcosis, in which an exotic, breathing gas mixture of $49 \%$ hydrogen, $50 \%$ helium and $1 \%$ oxygen is used (Abraini et al., 1994), so the safety of hydrogen for humans is fully proved. When delivered by a ventilator circuit, facemask or nasal cannula, hydrogen can be easily delivered via inhalation (Huang et al., 2010). In the first researches on the medical application of hydrogen, it was mainly administrated by inhalation. There were several advantages about hydrogen inhalation. First of all, inhaled hydrogen gas diffuses and acts more rapidly (Hong et al., 2010; Ohta, 2011). Second, 
inhalation of gas does not affect blood pressure (Ohsawa et al., 2007). Third, inhalation is a way to persistently administrate hydrogen. However, safety is a big concern in hydrogen inhalation. Although hydrogen poses no risk of explosion in air and in pure oxygen when its concentration is under $4 \%$ (Ohta, 2011), there is still risk in the storage, transportation, preparation and usage of hydrogen-oxygen mixture. Furthermore, a suit of complex apparatus is required for safety, and a strict operating rule must be developed to guarantee the safety of hydrogen inhalation.

\subsection{Oral intake of hydrogen-rich water}

In 2008, Nagata et al. placed water saturated with hydrogen (hydrogen water) into the stomach of a rat and found that hydrogen was detected at several micromole levels in blood and drinking hydrogen water prevented cognitive impairment by reducing oxidative stress (Nagata et al., 2009). Up to now, hydrogen-rich water has proven to be effective for various disease models, including atherosclerosis (Ohsawa et al., 2008), nephrotoxicity induced by an anti-cancer drug cisplatin (Nakashima-Kamimura et al., 2009), Parkinson's disease (Fu et al., 2009), colon inflammation (Kajiya et al., 2009) and cognitive impairment (Gu et al., 2010). It is detected that $\mathrm{H}_{2}$ can be dissolved in water up to $0.8 \mathrm{mM}$ under atmospheric pressure at room temperature (Ohta, 2011). Oral intake of hydrogen-rich water seems more practical in daily life and suitable for continuous consumption for preventive or therapeutic use, and it is found to have a comparable effect to hydrogen inhalation (Nakashima-Kamimura et al., 2009). Hydrogen water can be made by several methods, including dissolving hydrogen into water under high pressure and by reaction of magnesium with water, a method developed in Japan (Ohta, 2011).

\subsection{Injectable hydrogen-rich saline}

In 2008, our group first injected $\mathrm{H}_{2}$-saturated saline to rats and found that it could prevent neonatal hypoxia-ischemia injury (Cai et al., 2009). Soon after that, injected $\mathrm{H}_{2}$-saturated saline was found to be effective against various models, including intestinal ischemia/reperfusion injury (Zheng et al., 2009), acute pancreatitis (Chen et al., 2010), experimental liver injury (Sun et al., 2010) and carbon monoxide toxicity (Sun et al., 2011). It is anticipatable that injected hydrogen saline has potential in actual clinical treatment. The unique advantage of injectable hydrogen-rich saline is that it may provide more accurate concentrations of hydrogen and there is little evaporation or other kind of hydrogen lost (Cai et al., 2009).

\subsection{Production of hydrogen by intestinal bacteria}

It is noteworthy that endogenous hydrogen exists in humans and animals from anaerobic metabolism of bacteria in the large intestine (Maffel et al., 1977). Studies have shown that the hydrogen level in normal terminal breath is about 5-10 ppm, but in patients with lactose intolerance and bacterial disorders, it may achieve more than 90 ppm (Olson et al., 2002). The level of hydrogen has been measured in different organs of normal mice and it is found that in the large intestine, spleen, liver and gastric mucosa the level of hydrogen is very high. Drugs inhibiting the absorption of glucose in diabetics such as acarbose have a side effect of flatulence, but they often show a heart protective effect (Hanefeld et al., 2004). Recent studies 
showed that the main component of these gases is hydrogen, whose increase may contribute to the heart protective effect. Oral administration of turmeric (Shimouchi et al., 2009), milk (Shimouchi et al., 2009), a-glucosidase inhibitors (Suzuki et al., 2009), coral calcium hydride (Ueda et al., 2010), and mannitol (Liu et al., 2010) could also promote the production of endogenous hydrogen, which may be one of the mechanisms for treatment of some diseases. Moreover, it is reported that oral administration of a special designed bacteria producing hydrogen gas can prevent Con A-induced hepatitis, whereas the protective effect disappeared after antibiotic treatment, indicating that improving hydrogen production of intestinal bacteria can be a treatment of diseases (Kajiya et al., 2009). It seems that oral administration of these substances is far more cheap, convenient, comfortable and simpler than other ways to administer hydrogen.

\section{5 $\mathrm{H}_{2}$-Loaded eye drops and hydrogen bath}

In 2010, Oharazawa et al. dissolved $\mathrm{H}_{2}$ in saline as $\mathrm{H}_{2}$ loaded eye drops and found that it could ameliorate ischemia-reperfusion injury of the retina in a rat model by administering it to the ocular surface (Oharazawa et al., 2010). In 2011, Kubota used it to prevent oxidative stress-induced angiogenesis in a mouse corneal alkali-burn model with great success (Kubota et al., 2011). In Japan, taking a $\mathrm{H}_{2}$ water bath is another method to administrate $\mathrm{H}_{2}$ into the body in daily life. It is said that a 10 minutes bath is able to distribute $\mathrm{H}_{2}$ throughout the whole body (Ohta, 2011).

\section{Advantages and disadvantages of $\mathrm{H}_{2}$ treatment}

\subsection{Advantages}

Compared to traditional antioxidants, hydrogen, the newly explored antioxidant, obtains a number of advantages. First, due to its small molecular weight, hydrogen can easily penetrate biomembranes and diffuse into the cytosol, mitochondria and nucleus, which are the main site of ROS generation and DNA damage (Ohsawa et al., 2007), but difficult to targeted by other drugs. Second, as hydrogen selectively reacts with $\bullet \mathrm{OH}$ and ONOO-, other important ROS (e.g. $\mathrm{H}_{2} \mathrm{O}_{2}$ and $\mathrm{O}_{2-}$ ) and $\mathrm{NO}$ involved in cell signaling are not decreased, so the metabolic oxidation-reduction reactions are not disturbed. As we know, $\mathrm{O}_{2}$ and $\mathrm{H}_{2} \mathrm{O}_{2}$ have important functions in neutrophils and macrophages (Ohsawa et al., 2007). Because of the hypo-reactivity of them, hydrogen does not disturb the innate immune system and allow phagocytosis of infecting organisms. Also, as endogenous NO plays an important role in vasodilation, vasoconstriction and leukocyte/endothelial interactions, it may be beneficial to spare endogenous NO (Pinsky et al., 1994; Huang et al., 2010). Third, hydrogen is better tolerated than many other antioxidants. Forth, it is found that hydrogen doesn't influence physiological parameters in the blood (temperature, blood pressure, $\mathrm{pH}$, $\mathrm{pO}_{2}$ ) (Hong et al., 2010). Fifth, compared to other drugs, the cost of hydrogen therapy is much lower. All of these properties of hydrogen make administration of hydrogen water a promising and treatment for various diseases.

\subsection{Disadvantages}

Every drug has its disadvantages; hydrogen is not an exception. For hydrogen inhalation, the main concern may be the risk of explosion. Although hydrogen won't explore under the 
concentration $4.6 \%$, there is still risk of explosion during storing, transportation and dispensing. Furthermore, a complicated appliance is required for it. For hydrogen water injection, the main disadvantage may be the compliance of patients. The proper administration time, ways and dosages of hydrogen saline injection are other concerns. Oral administration of hydrogen water may be a better choice, but some evidences showed that there might be some adverse effects as well. It was found that there were a few changes in hematology and clinical chemistry parameters (Saitoh et al., 2010). In human trials, slight decreases in aspartate aminotransferase and alanine aminotransferase and increases in gammaglutamyl transferase and total bilirubin were observed (Nakao et al., 2010). Other symptoms, such as loose stools, increase in frequency of bowel movement, heartburn and headache were also experienced by some people who drunk hydrogen water (Nakao et al., 2010; Huang et al., 2010).

\section{Not solved problems of $\mathrm{H} 2$ as a therapeutic agent}

First of all, as we mentioned above, growing number of evidence suggest that ROS scavenging properties are unlikely to be the only explanation for the effects of hydrogen (Huang et al., 2010). Other not yet defined biological mechanisms of hydrogen as a signaling molecule need exploring. Some additional issues, such as, how $\mathrm{H}_{2}$ involves the cross-talk among anti-oxidation, anti-inflammation and anti-allergy, what is the primary molecular target of $\mathrm{H}_{2}$, remain unknown (Ohta, 2011). Secondly, although the protective effects of $\mathrm{H}_{2}$ have been proved in clinical trials, well designed and large-scale clinical studies are required to explore ideal dose, timing and delivery methods (Huang et al., 2010). Thirdly, we need to explore the pharmacokinetics, biology and toxicity of hydrogen to well apply it clinically (Huang et al., 2010). Fourthly, although several ways to administrate hydrogen have been explored, no one has seriously compared their advantages and disadvantages in clinical trials. An ideal administration method should be selected out for clinical application.

\section{References}

Abraini, J.H., Gardette-Chauffour, M.C., Martinez, E., Rostain, J.C., \& Lemaire, C. (1994). Psychophysiological reactions in humans during an open sea dive to $500 \mathrm{~m}$ with a hydrogen-helium-oxygen mixture. J Appl Physiol, Vol. 76, No.3, pp.1113-1118.

Atsushi, H., Inaba, H., Suzuki, E., Kasai1, K., Suzuki, H., Shinohara, A., Shirao, M., Kubo, K., \& Yoshimura, Y. (2010). In vitro physicochemical properties of neutral aqueous solution systems (water products as drinks) containing hydrogen gas, 2carboxyethyl germanium sesquioxide, and platinum nanocolloid as additives. $J$ Health Sci, Vol. 56, No. 2, pp.167-174.

Buchholz, B.M., Kaczorowski, D.J., Sugimoto, R., Yang, R., Wang, Y., Billiar, T.R., McCurry, K.R., Bauer, A.J., \& Nakao, A. (2008). Hydrogen inhalation ameliorates oxidative stress in transplantation induced intestinal graft injury. Am J Transplant, Vol.8, No.10, pp.2015-24.

Cai, J., Kang, Z., Liu, K., Liu, W., Li, R., Zhang, J.H., Luo, X., \& Sun X. (2009). Neuroprotective effects of hydrogen saline in neonatal hypoxia-ischemia rat model. Brain Res, Vol. 1256, pp.129-137.

Chen, H., Sun, Y.P., Li, Y., Liu, W.W., Xiang, H.G., Fan, L.Y., Sun, Q., Xu, X.Y., Cai, .JM., Ruan, C.P., Su, N., Yan, R.L., Sun, X.J., \& Wang, Q. (2010). Hydrogen-rich saline 
ameliorates the severity of 1-arginine-induced acute pancreatitis in rats. Biochem Biophys Res Commun, Vol. 393, No. 2, pp.308-13.

Dole, M., Wilson, F.R., \& Fife, W.P. (1975). Hyperbaric hydrogen therapy a possible treatment for cancer. Science, Vol. 190, No. 4210, pp.152-4.

Fu, Y., Ito, M., Fujita, Y., Ito, M., Ichihara, M., Masuda, A., Suzuki, Y., Maesawa, S., Kajita, Y., Hirayama, M., Ohsawa, I., Ohta, S., \& Ohno, K. (2009). Molecular hydrogen is protective against 6-hydroxydopamine-induced nigrostriatal degeneration in a rat model of Parkinson's disease. Neurosci Lett, Vol. 453, No. 2, pp.81-85.

Fukuda, K., Asoh, S., Ishikawa, M., Yamamoto, Y., Ohsawa, I., \& Ohta, S. (2007). Inhalation of hydrogen gas suppresses hepatic injury caused by ischemia/reperfusion through reducing oxidative stress. Biochem Biophys Res Commun; Vol. 361, No.3, pp.670-674.

Gharib, B., Hanna, S., Abdallahi, O.M., Lepidi, H., Gardette, B., \& De Reggi, M. (2001). Antiinflammatory properties of molecular hydrogen investigation on parasite-induced liver inflammation. C R Acad Sci III, Vol. 324, No. 8, pp.719-24.

Gu, Y., Huang, C.S., Inoue, T., Yamashita, T., Ishida, T., Kang, K.M., \& Nakao, A. (2010). Drinking hydrogen water ameliorated cognitive impairment in senescenceaccelerated mice. J Clin Biochem Nutr, Vol. 46, No. 3, pp.269-76.

Hanefeld, M., Cagatay, M., Petrowitsch, T., Neuser, D., \& Petzinna, D., Rupp, M. (2004). Acarbose reduces the risk for myocardial infarction in type 2 diabetic patients meta-analysis of seven long-term studies. Eur Heart J, Vol. 25, No.1, pp.10-16.

Hayashida, K., Sano, M., Ohsawa, I., Shinmura, K., Tamaki, K., Kimura, K., Endo, J., Katayama, T., Kawamura, A., Kohsaka, S., Makino, S., Ohta, S., Ogawa, S., Fukuda, K. (2008). Inhalation of hydrogen gas reduces infarct size in the rat model of myocardial ischemia-reperfusion injury. Biochem Biophys Res Commun, Vol. 373, No.1, pp.30-35.

Huang, C.S., Kawamura, T., Toyoda, Y., Nakao, A. (2010). Recent advances in hydrogen research as a therapeutic medical gas. Free Radic Res, Vol. 44, No. 9, pp.971-982.

Hong, Y., Chen, S., Zhang, J.M. (2010). Hydrogen as a selective antioxidant a review of clinical and experimental studies. J Int Med Res, Vol. 38, No. 6, pp.1893-1903.

Itoh, T., Funjita, Y., Ito, M., Masuda, A., Ohno, K., Ichihara, M., Kojima, T., Nozawa, Y., Ito, M. (2009). Molecular hydrogen suppresses FceRI-mediated signal transduction and prevents degranulation of mast cells. Biochem Biophys Res Commun, Vol. 389, No. 4, pp.651-656.

Itoh, T., Hamada, N., Terazawa, R., Ito, M., Ohno, K., Ichihara, M., Nozawa, Y. (2011). Molecular hydrogen inhibits lipopolysaccharide /interferon $\gamma$-induced nitric oxide production through modulation of signal transduction in macrophages. Biochem Biophys Res Commun, Vol. 411, No. 1,pp.143-149.

Kajiya, M., Sato, K., Silva, M.J., Ouhara, K., Do, P.M., Shanmugam, K.T., Kawai, T. (2009). Hydrogen from intestinal bacteria is protective for Concanavalin A-induced hepatitis. Biochem Biophys Res Commun, Vol. 386, No.2, pp.316-321.

Kajiya, M., Silva, M.J., Sato, K., Ouhara, K., Kawai, T. (2009). Hydrogen mediates suppression of colon inflammation induced by dextran sodium sulfate. Biochem Biophys Res Commun, Vol. 386, No. 1, pp.11-15. 
Kawamura, T., Huang, C.S., Peng, X, Masutani, K., Shigemura, N., Billiar, T.R., Okumura, M., Toyoda, Y., Nakao, A. ( 2011). The effect of donor treatment with hydrogen on lung allograft function in rats. Surgery, Vol. 150, No. 2, pp. 240-9.

Kubota, M., Shimmura, S., Kubota, S., Miyashita, H., Kato, N., Noda, K., Ozawa, Y., Usui, T., Ishida, S., Umezawa, K., Kurihara, T., Tsubota, K. (2011). Hydrogen and N-acetylL-cysteine rescue oxidative stress-induced ngiogenesis in a mouse corneal alkaliburn model. Invest Ophthalmol Vis Sci, Vol. 52, No.1, pp.427-433.

Liu, S., Sun, Q., Tao, H., Sun, X. (2010). Oral administration of mannitol may be an effective treatment for ischemia-reperfusion injury. Med Hypotheses. Vol. 75, No. 6, pp.620-622.

Maffel, H.V., Metz, G., Bampoe, V., Shiner, M., Herman, S., Brook, C.G. (1977). Lactose intolerance, detected by the hydrogen breath test, in infants and children with chronic diarrhoea. Arch Dis Child, Vol. 52, No. 10, pp.766-771.

Mao, Y.F., Zheng, X.F., Cai, J.M., You, X.M., Deng, X.M., Zhang, J.H., Jiang, L., Sun, X.J. (2009). Hydrogen-rich saline reduces lung injury induced by intestinal ischemia/reperfusion in rats. Biochem Biophys Res Commun, Vol. 381, No.4, pp.602-605.

Nagata, K., Nakashima-Kamimura, N., Mikami, T., Ohsawa, I., Ohta, S. (2009). Consumption of molecular hydrogen prevents the stress-induced impairments in hippocampus-dependent learning tasks during chronic physical restraint in mice. Neuropsychopharmacology. Vol. 34, No. 2, pp.501-508.

Nakao, A., Sugimoto, R., Billiar, T.R., McCurry, K.R. (2009). Therapeutic antioxidant medical gas. J Clin Biochem Nutr. Vol. 44, No. 1, pp.1-13.

Nakao, A., Toyoda, Y., Sharma, P., Evans, M., Guthrie, N. (2010). Effectiveness of hydrogen rich water on antioxidant status of subjects with potential metabolic syndrome-an open label pilot study. J Clin Biochem Nutr, Vol. 46, No.2, pp.140-149.

Nakashima-Kamimura, N., Mori, T., Ohsawa, I., Asoh, S., Ohta, S. (2009). Molecular hydrogen alleviates nephrotoxicity induced by an anti-cancer drug cisplatin without compromising anti-tumor activity in mice. Cancer Chemother Pharmacol, Vol. 64, No.4, pp.753-761.

Oharazawa, H., Igarashi, T., Yokota, T., Fujii, H., Suzuki, H., Machide, M., Takahashi, H., Ohta, S., Ohsawa, I. (2010). Protection of the retina by rapid diffusion of hydrogen administration of hydrogen-loaded eye drops in retinal ischemia-reperfusion injury. Invest Ophthalmol Vis Sci, Vol. 51, No.1, pp.487-492.

Ohsawa, I., Ishikawa, M., Takahashi, K., Watanabe, M., Nishimaki, K., Yamagata, K., Katsura, K., Katayama, Y., Asoh, S., Ohta, S. (2007). Hydrogen acts as a therapeutic antioxidant by selectively reducing cytotoxic oxygen radicals. Nat Med, Vol.13, No.6, pp.688-694.

Ohsawa, I., Nishimaki, K., Yamagata, K., Ishikawa, M., Ohta, S. (2008). Consumption of hydrogen water prevents atherosclerosis in apolipoprotein E knockout mice. Biochem Biophys Res Commun, Vol. 377, No. 4, pp.1195-1198.

Ohta, S. (2011). Recent progress toward hydrogen medicine potential of molecular hydrogen for preventive and therapeutic applications. Curr Pharm Des, [Epub ahead of print].

Olson, J.W., Maier, R.J. (2002). Molecular hydrogen as an energy source for Helicobacter pylori. Science, Vol. 298, No. 5599, pp.1788-1790.

Pinsky, D.J., Naka, Y., Chowdhury, N.C., Liao, H., Oz, M.C., Michler, R.E., Kubaszewski, E., Malinski, T., Stern, D.M. (1994). The nitric oxide/cyclic GMP pathway in organ 
transplantation critical role in successful lung preservation. Proc Natl Acad Sci USA, Vol. 91, No.25, pp.12086-12090.

Sobko, T., Norman, M., Norin, E., Gustafsson, L.E., Lundberg, J.O. (2005). Birth-related increase in intracolonic hydrogen gas and nitric oxide as indicator of host-microbial interactions. Allergy, Vol. 60, No. 3, pp.396-400.

Sun, H., Chen, L., Zhou, W., Hu, L., Li, L., Tu, Q., Chang, Y., Liu, Q., Sun, X., Wu, M., Wang, $\mathrm{H}$. (2011). The protective role of hydrogen-rich saline in experimental liver injury in mice. J Hepatol, Vol. 54, No. 3, pp.471-480.

Sun, Q., Cai, J., Zhou, J., Tao, H., Zhang, J.H., Zhang, W., Sun, X.J. (2011). Hydrogen-rich saline reduces delayed neurologic sequelae in experimental carbon monoxide toxicity. Crit Care Med, Vol. 39, No. 4, pp.765-769.

Shimouchi, A., Nose, K., Takaoka, M., Hayashi, H., Kondo, T. (2009). Effect of dietary turmeric on breath hydrogen. Dig Dis Sci. Vol. 54, No. 8, pp.1725-9.

Shimouchi, A., Nose, K., Yamaguchi, M., Ishiguro, H., Kondo, T. (2009). Breath hydrogen produced by ingestion of commercial hydrogen water and milk. Biomark Insights, Vol. 4, pp.27-32.

Suzuki, Y., Sano, M., Hayashida, K., Ohsawa, I., Ohta, S., Fukuda, K. (2009). Are the effects of alpha-glucosidase inhibitors on cardiovascular events related to elevated levels of hydrogen gas in the gastrointestinal tract? FEBS Lett, Vol. 583, No.13, pp.2157-2159.

Saitoh, Y., Harata, Y., Mizuhashi, F., Nakajima, M., Miwa, N. (2010). Biological safety of neutral-pH hydrogen-enriched electrolyzed water upon mutagenicity, genotoxicity and subchronic oral toxicity. Toxicol Ind Health, Vol. 26, No.4, pp.203-216.

Ueda, Y., Nakajima, A., Oikawa, T. (2010). Hydrogen-related enhancement of in vivo antioxidant ability in the brain of rats fed coral calcium hydride. Neurochem Res, Vol. 35, No. 10, pp.1510-1515.

Wood, K.C., Gladwin, M.T. (2007). The hydrogen highway to reperfusion therapy. Nat Med, Vol. 13, No. 6, pp.673-674.

Wang, C., Li, J., Liu, Q., Yang, R., Zhang, J.H., Cao, Y.P., Sun, X.J. (2011). Hydrogen-rich saline reduces oxidative stress and inflammation by inhibit of JNK and NF-kB activation in a rat model of amyloid-beta-induced Alzheimer's disease. Neurosci Lett, Vol. 491, No. 2, pp.127-132.

Zheng, X., Mao, Y., Cai, J., Li, Y., Liu, W., Sun, P., Zhang, J.H., Sun, X., Yuan, H. (2009). Hydrogen-rich saline protects against intestinal ischemia/reperfusion injury in rats. Free Radic Res, Vol. 43, No. 5, pp.478-84. 


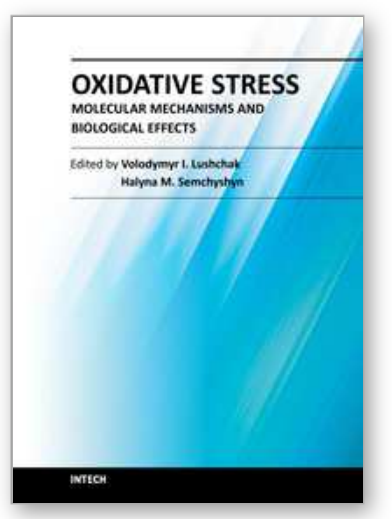

\author{
Oxidative Stress - Molecular Mechanisms and Biological Effects \\ Edited by Dr. Volodymyr Lushchak
}

ISBN 978-953-51-0554-1

Hard cover, 362 pages

Publisher InTech

Published online 25, April, 2012

Published in print edition April, 2012

Since the discovery of free radicals in biological systems researchers have been highly interested in their interaction with biological molecules. Denoted in 1980, and due to fruitful results and ideas, oxidative stress is now appreciated by both basic and applied scientists as an enhanced steady state level of reactive oxygen species with wide range of biological effects. This book covers a wide range of aspects and issues related to the field of oxidative stress. The association between generation and elimination of reactive species and effects of oxidative stress are also addressed, as well as summaries of recent works on the signaling role of reactive species in eukaryotic organisms. The readers will gain an overview of our current understanding of homeostasis of reactive species and cellular processes they are involved in, as well as useful resources for further reading.

\title{
How to reference
}

In order to correctly reference this scholarly work, feel free to copy and paste the following:

Shulin Liu, Xuejun Sun and Hengyi Tao (2012). Hydrogen: From a Biologically Inert Gas to a Unique Antioxidant, Oxidative Stress - Molecular Mechanisms and Biological Effects, Dr. Volodymyr Lushchak (Ed.), ISBN: 978-953-51-0554-1, InTech, Available from: http://www.intechopen.com/books/oxidative-stressmolecular-mechanisms-and-biological-effects/hydrogen-from-a-biologically-inert-gas-to-a-unique-antioxidant

\section{INTECH}

open science | open minds

\author{
InTech Europe \\ University Campus STeP Ri \\ Slavka Krautzeka 83/A \\ 51000 Rijeka, Croatia \\ Phone: +385 (51) 770447 \\ Fax: +385 (51) 686166 \\ www.intechopen.com
}

\author{
InTech China \\ Unit 405, Office Block, Hotel Equatorial Shanghai \\ No.65, Yan An Road (West), Shanghai, 200040, China \\ 中国上海市延安西路65号上海国际贵都大饭店办公楼 405 单元 \\ Phone: +86-21-62489820 \\ Fax: +86-21-62489821
}


(C) 2012 The Author(s). Licensee IntechOpen. This is an open access article distributed under the terms of the Creative Commons Attribution 3.0 License, which permits unrestricted use, distribution, and reproduction in any medium, provided the original work is properly cited. 